\title{
Modeling of the process of kneading the yeast dough by cam operating elements
}

\section{Vitalii Rachok ${ }^{1}$, Volodymyr Telychkun ${ }^{1}$, Yevgenii Shtefan ${ }^{1}$, Yuliya Telychkun ${ }^{1}$, Stanka Damyanova}

\author{
1 - National University of food Technologies, Kyiv, Ukraine \\ 2 - Ruse University "Angel Kancev", branch Razgrad, Bulgaria
}

\section{Keywords:}

Dough

Kneading

Modeling

Cam

\section{Article history:}

Received 10.08.2018

Received in revised

form 01.12.2018

Accepted 31.05.2019

\section{Corresponding}

author:

Vitalii Rachok

E-mail:

RachokV3478@

gmail.com

DOI: $10.24263 / 2304-$ 974X-2019-8-2-14

\section{Abstract}

Introduction. A mathematical model was developed and simulation modeling of the process of kneading the yeast dough by cam operating elements was carried out.

Materials and methods. The conditions of the contact interaction of the material with the working elements and the chamber of kneading, as well as the value of the dough structuralmechanical characteristics were specified. During the simulation of the kneading process, the angular position of the cam element was changed from $90^{\circ}$ to $585^{\circ}$.

Results and discussion. The scheme of the mathematical modeling of the process of mixing of the yeast dough in a dough machine of continuous action is developed. Based on the results of simulation of the mixing process, cam operating elements, the distribution of strain of displacement and dissipation of yeast dough in the working chamber were obtained. As the angle of the position $\left(90^{\circ}\right.$ to $\left.360^{\circ}\right)$ of the cam element increases on the shaft, there is an increase in the shear stress. The greatest indices of shear stress occur in the area of cam clamping elements and in the contact area of the cam with the walls of the case, numerical values reach within 7000-8000 $\mathrm{Pa}$. For the rest of the camera, the displacement stress reaches 1000-3000 Pa. Distribution of dissipation shows that in parts of the working chamber there is the formation of heat in the area of flow. With the increase of the angle of the cam (from $180^{\circ}$ to $585^{\circ}$ ) of the cam element, there is a gradual increase in temperature. At the site of mixing 12 pairs of cams, the temperature of the yeast dough increases by almost $5{ }^{\circ} \mathrm{C}$. Taking into account that before the simulation, the initial temperature reached $\mathrm{t}=30^{\circ} \mathrm{C}$, and upon completion of the mixing process did not exceed $35^{\circ} \mathrm{C}$, the pastry preparation parameters were observed. The greatest heat release occurs in the area of the cam clamping elements.

The results of mathematical modeling are confirmed by physical experiments on a test dough mixing machine of continuous action, an error within $5 \%$.

Conclusions. The proposed simulation scheme allows us to investigate the process of mixing the yeast dough according to various technological parameters. The obtained results give the initial data for the choice of rational parameters of the process of mixing the yeast dough by the cam working elements. 


\section{Introduction}

Mathematical modeling is an important tool in scientific research, but previously it was not used during the study of the process of mixing the yeast dough [18] by cam operating elements. The cam elements are gaining widespread acceptance, we have carried out a series of experimental studies that prove their effectiveness during the kneading process. During the viscous flow, the deformation is proportional to the stress imposed by Newton's law, and after the removal of the load is not restored [1-2]. Plastic deformation is created under stress that exceeds a certain limit value (the boundary of flowability), to which the material behaves as visco-elastic [4].

During mixing flour with water, the components of the flour form a hydrated bonded mass - a dough. Hydrated medium, which is a dough, the presence in this mass of introduced fermentable microflora is triggered by a system of complex biochemical, microbiological, colloidal and other processes [5-6].

Physical-mechanical processes take place at the dip under the influence of the master body, which mixes particles of flour, water, yeast suspension and solutions of raw materials, providing the interaction of all the constituents of the components of the formulation. By numerical studies it was found that an increase of the mechanical effect on the dough during the dipping affects its rheological properties [7-8].

The cam working elements are becoming more widely used, but almost nonexploratory, requiring in-depth study and detailed analysis. By way of a critical analysis of literary sources on the subject of the process of mixing, the directions of development and improvement of this issue were identified, thus a deep and systematic study requires the problem of qualitative and intensive mixing of yeast dough in continuous-dough machines of continuous action [9].

A scientific review of constructions of dough machines and their components, has revealed the main advantages and disadvantages of design solutions in the design and operation of continuous machines of continuous action [12]. The main disadvantages include, in addition to the local problems inherent in each machine, the basic ones that are presently present in most dough machines of continuous action, such as uneven mixing of the components of the formulation components at the first stage and the lack of qualitative plasticization of the dough in the third stage, also existing the problem is excessive heating of the dough with intense kneading of the dough [14-15].

Based on the theoretical researches and the obtained research results, after the comparative analysis of the working elements, there was decided to model the process of kneading the yeast wheat dough with the use of cam operating elements.

\section{Materials and methods}

\section{Software simulation process}

The mathematical modeling of the process of kneading wheat yeast dough by cam operating organs was carried out in the software complex GiPex 3D V17.

To simplify the mathematical description of the mechanical behavior of the dough for the corresponding parameters, the spatial averaging over the solid and gas phases was used.

Mathematical dependencies, geometric dimensions of the chamber, geometrical sizes of cam operating bodies, frequency of rotation, and experimental data obtained after a physical experiment were given to calculate and simulate the simulation of the process of mixing the yeast dough with cam operating organs into the GiPex 3D V17 software complex. 


\section{Structure of yeast dough}

The dough is considered as a complex colloidal system, consisting of several continuous and periodic phases. Solids and liquids (gluten and water) in the dough are continuous phases, starch grains and gas formed during fermentation of the dough - a periodic phase. As a result, the physical properties of the dough are characterized by parameters of solids, liquids, gases and indicators resulting from the interaction of these phases. This process is carried out by mechanical processing of the dough, and consists in swelling of starch and protein complex with the formation of an elastic-elastic-viscous homogeneous mass containing active-active microorganisms and enzymes.

\section{Simulation of the process of kneading yeast dough}

The mathematical modeling of the process of mixing the yeast dough by cam operating elements was carried out with the help of the use of a modern software complex, in which the predicted equations of the movement of the yeast dough, the geometrical parameters of the chamber of kneading and cam working elements.

A mathematical model was selected for modeling the process of kneading wheat yeast dough, which is used to study the processes in which elastic, viscous and plastic deformations of dispersed, saturated materials occur during non-stationary regime of power load.

The area to which the ideology of the continuous medium can be applied will be called the characteristic volume, identifying with the proportion of the dough that is kneading. We will assume that the size of this element is much smaller than the sample size for research, and the entire volume can be typed from similar elements. To simplify the mathematical description of the mechanical behavior of the dough for the corresponding parameters we will use spatial averaging over the solid and gas phases.

Let us consider a certain characteristic volume V bounded by the surface $\Omega$, occupied by a diphasic moving substance (Figure 2) [9-10].

That is, part of this volume $\mathrm{V}_{1}$ is occupied by the first (solid-liquid) phase, and the second part of $\mathrm{V}_{2}$ is the gas phase, $\left(\mathrm{V}=\mathrm{V}_{1}+\mathrm{V}_{2}\right)$. Similarly, the part of the boundary surface $\Omega_{1}$ belongs to the solid phase, and the other $\Omega_{2}$ is the gas; $\Omega=\Omega_{1}+\Omega_{2}$. Within the volume $\mathrm{V}$ there is (in the general case, a lot of bonds) the phase surface section $\Omega i j(i, j=1,2 ; i \neq j$ ). In the model description of the mechanical behavior of the disperse material in the process of force loading we use the hypothesis of its continuity within the equation of conservation of mass [10].

Mathematical dependencies, geometric dimensions of the chamber, geometrical sizes of cam operating elements, frequency of rotation, and experimental data obtained after a physical experiment were given to calculate and simulate the simulation of the process of mixing the yeast dough with cam operating elements.

At the stage of formation of the exercise, the conditions of the contact interaction of the material with the working elements and the chamber of mixing, as well as the values of the structural-mechanical characteristics of the dough (Table 1) are given.

To simulate the process, a calculated grid was used. The cam working elements rotated with a frequency of $60 \mathrm{rpm}$ in the opposite direction and changed the angle by $45^{\circ}$ (Figure 2). After the mechanical action by cam operation elements the share rate and dissipation were calculated via the software complex.

After entering into the software complex all the necessary parameters, the process of calculating and visualizing the process of mixing the yeast dough begins. 


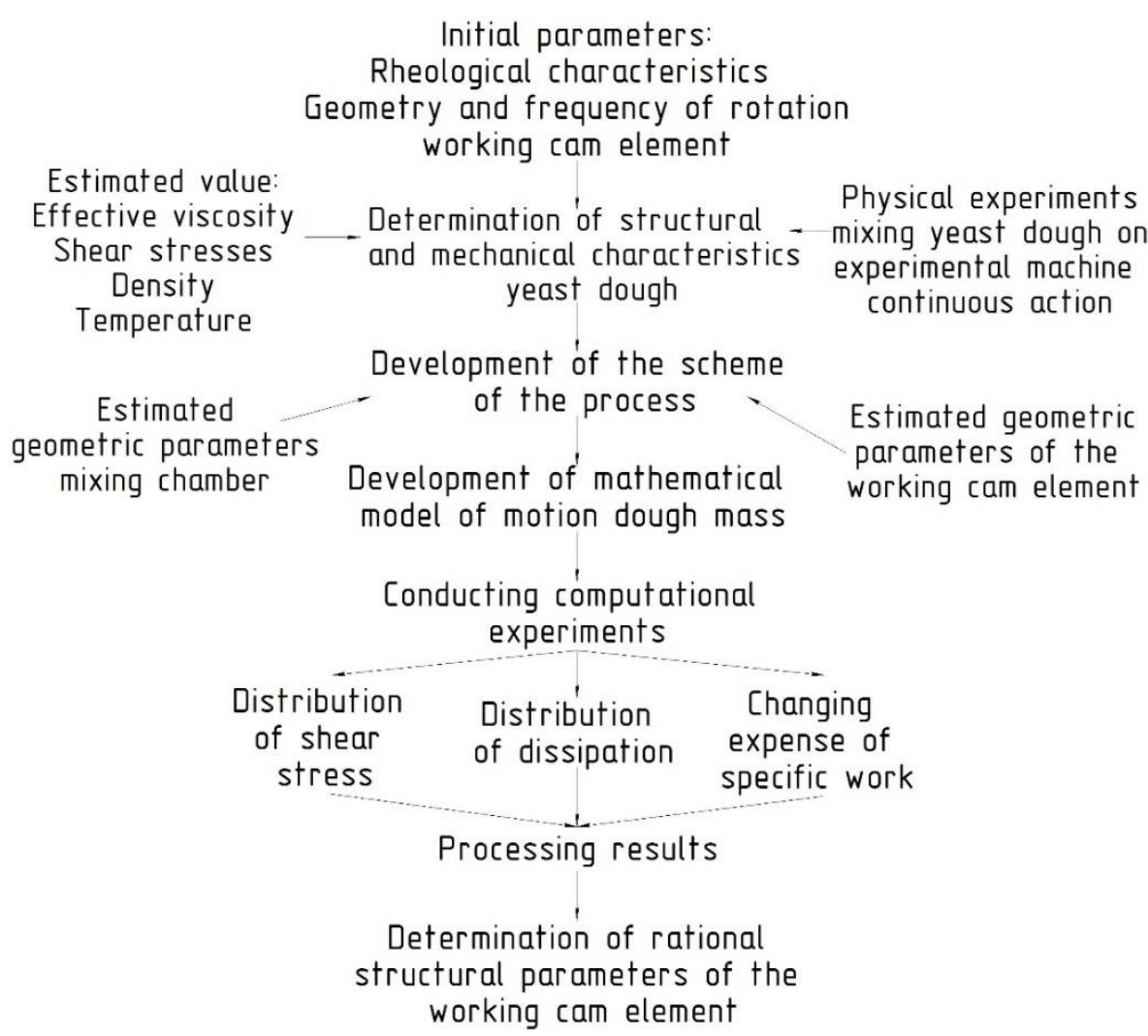

Figure 1. Scheme of simulation of the process of kneading yeast dough in a dough machine of continuous action

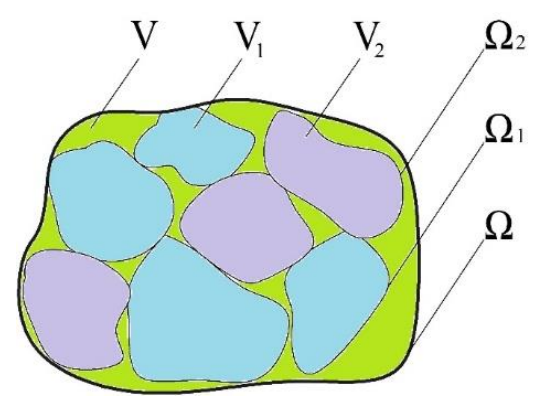

Figure 2. Characteristic volume V.

$\mathrm{V}_{1}$ is the volume of the solid-liquid phase, $\mathrm{V}_{2}$ is the volume of the gas phase,

$\Omega_{1}$ is the boundary surface of the solid-liquid phase,

$\Omega_{2}$ is the boundary surface of gas phase 
Output data before calculation the process of kneading wheat yeast dough
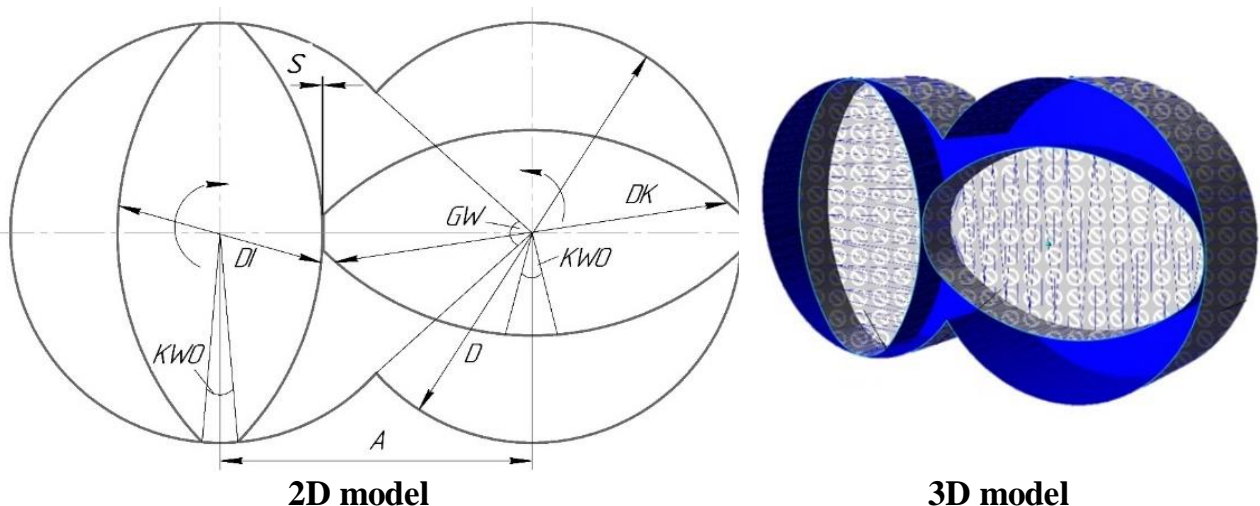

3D model

Figure 3. Specified geometric dimensions mixing chamber and located therein cam working elements

Table 1

Output data before calculation the process of kneading wheat yeast dough by cam operating elements

\begin{tabular}{|c|c|c|}
\hline Variable & Symbol & Calculation \\
\hline Number of cams & $\mathrm{Z}$ & Given by the condition \\
\hline The distance between the centers & $\mathrm{A}$ & Given by the condition \\
\hline Diameter of the mixing chamber & $\mathrm{D}$ & Given by the condition \\
\hline Step of the cams & $\mathrm{T}$ & Given by the condition \\
\hline $\begin{array}{l}\text { The gap between the top of the cam } \\
\text { and the cylinder wall }\end{array}$ & $\Sigma$ & Given by the condition \\
\hline The gap between the cams & $\mathrm{s}$ & Given by the condition \\
\hline The radius of the working chamber & RG & $\mathrm{RG}=\mathrm{D} / 2$ \\
\hline Work camera angle & GW & $\mathrm{GW}=2 \operatorname{acos}(\mathrm{A} / \mathrm{D})$ \\
\hline The outer diameter of the cam & DA & $\mathrm{DA}=\mathrm{DG}-2 \mathrm{~s}$ \\
\hline The diameter of the core of the cam & DK & $\mathrm{DK}=2 \mathrm{~A}-\mathrm{DA}-2 \mathrm{~s}$ \\
\hline The outer diameter of the cam & $\mathrm{DE}$ & $\mathrm{DE}=\mathrm{DA}+\mathrm{s}$ \\
\hline The diameter of the core of the cam & DI & $\mathrm{DI}=2 \mathrm{~A}-\mathrm{DE}$ \\
\hline $\begin{array}{l}\text { Angle of inclination, completely } \\
\text { tangent }\end{array}$ & KW0 & $\mathrm{KW} 0=180^{\circ} / \mathrm{Z}-\mathrm{FW} 0$ \\
\hline Angle of inclination, actual & FW1 & $\mathrm{FW} 1=180^{\circ} / \mathrm{Z}-(\mathrm{NW}+\mathrm{KW} 1) / 2$ \\
\hline The width of the top, the actual & KB1 & $\mathrm{KB} 1=\mathrm{KW} 1 /(2 \pi) \mathrm{T}$ \\
\hline Marginal shear stress & $\mathrm{G}_{0}$ & $\mathrm{G}_{0}=1,49 \cdot 10^{-4} \mathrm{MPa}$ \\
\hline Young's module & $\mathrm{E}$ & $\mathrm{E}=9,2 \cdot 10^{-4} \mathrm{MPa}$ \\
\hline Poisson's coefficient & $v$ & $v=0,4$ \\
\hline Effective dough viscosity & $\eta_{\mathrm{e \phi}}$ & $\eta=3220 \gamma^{-0,85}$ \\
\hline The initial temperature of the dough & $t_{0}$ & $\mathrm{t}_{0}=30^{\circ} \mathrm{C}$ \\
\hline Density of the dough & $\rho$ & $\rho=1400 \mathrm{~kg} / \mathrm{m}^{3}$ \\
\hline Rotation frequency WE & $\mathrm{n}$ & $\mathrm{n}=60 \mathrm{rpm}$ \\
\hline
\end{tabular}




\section{Results and discussion}

\section{Terms movement of the cam working element}

Information technology design allows us to consider the technological process of mixing the yeast dough in the form of a system of interconnected objects of study (Figure 5)

Modeling of the process of mixing the yeast dough by the cam operating elements passes with a rotational speed of $60 \mathrm{rpm}$ in a dual capacitive capacity. The cam's working elements turn to meet each other by kneading the yeast dough, moving the yeast dough in the crucible with the use of cam-like elements is depicted in Figure 4.

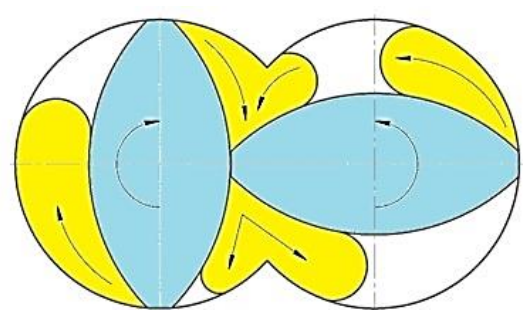

$90^{\circ}$ rotation

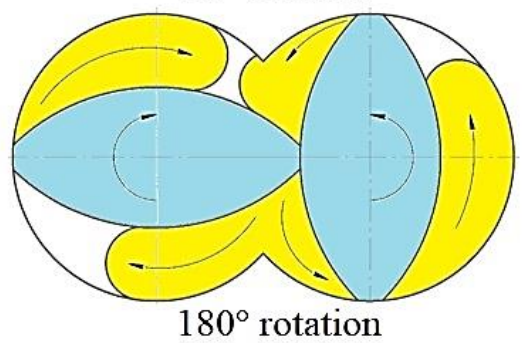

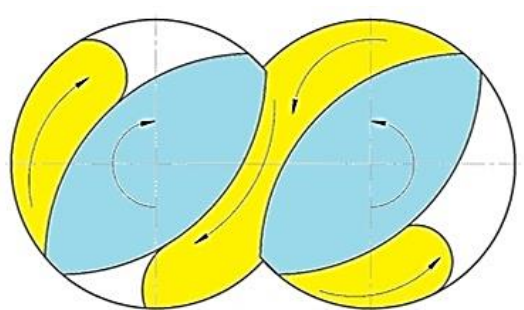

$135^{\circ}$ rotation

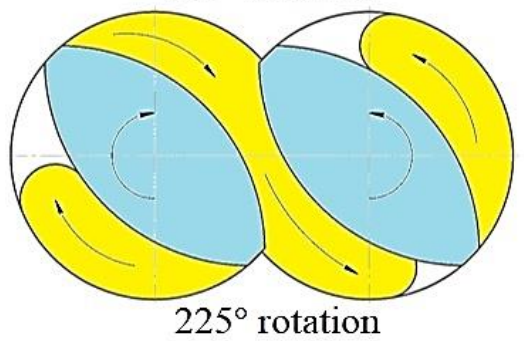

Figure 4. Moving the yeast dough in the crucible with the use of cam operating elements

Simulation of the process of mixing the yeast dough is needed for further calculation of the design, technological parameters and recommendations for the design of the working element and dough machine in general. Using simulation, we will determine the range of variation of the bias voltage and dissipation parameters. The purpose of which is to establish the rational value of the selected parameters in order to achieve the maximum effect from their effect on the process of kneading.

\section{Design blocks of the kneading process}

The initial data and boundary conditions were entered for simulation modeling of the process of mixing into the software complex, namely, to the calculation blocks (Figure 5): material properties, geometry and status of the process of mixing [11].

In the properties of the material, a two-component mixture with the properties of the pseudoplastic fluid was chosen. Geometric data are given in the geometry block and in the calculation parameters the counter-rotation of the cam's working bodies is selected. The mixing process status is selected as complete, not stable, alternating during mixing. 


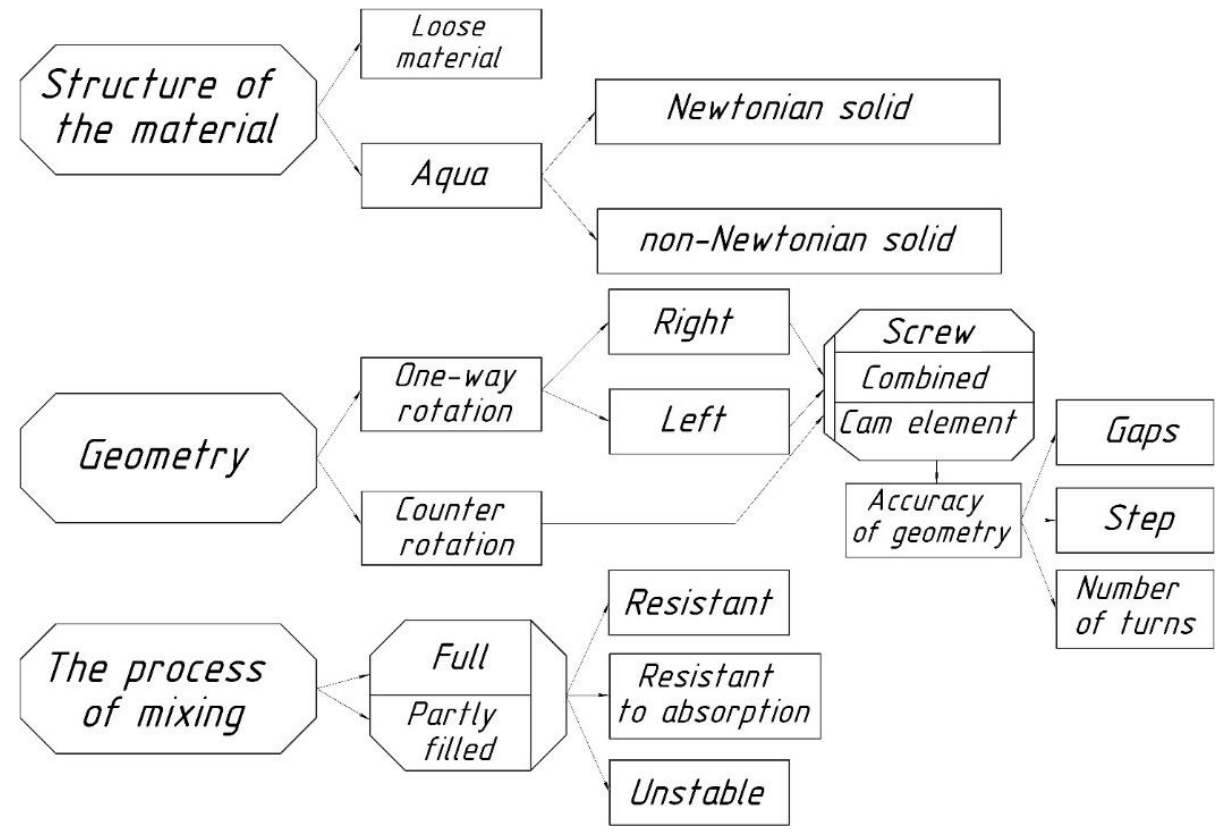

Figure 5. Scheme of imitative modeling of the process of mixing by cam operating elements

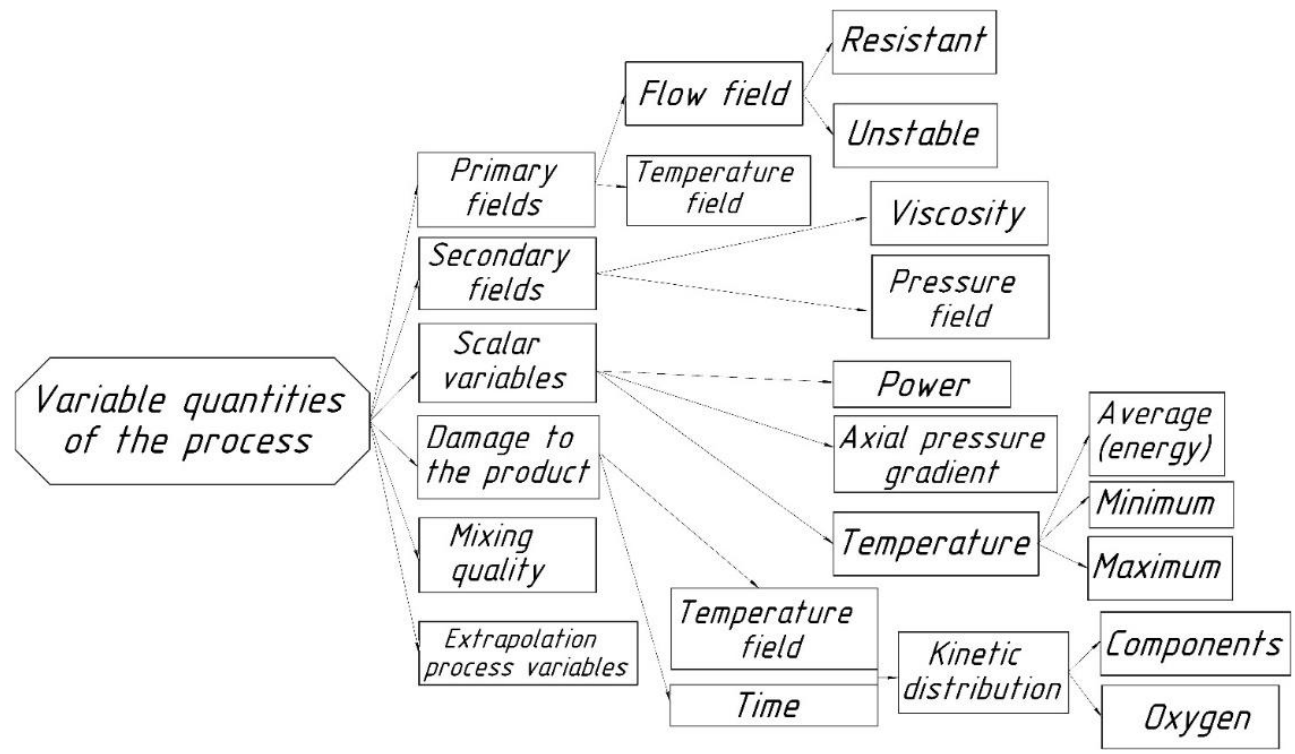

Figure 6. Depth of simulation modeling of the process of kneading by cam operating elements. 
Using the depth of simulation (Figure 6) of the kneading process, we obtained a change in the shear stress and the distribution of dissipation in the crucible during the kneading of the yeast dough by cam operating elements.

Along with the characteristics of displacement and power, the mechanical characteristics of the voltage on the yeast dough are key features. The mechanical stress is characterized by the distribution of the shear stress on the yeast dough within the mixing chamber [8].

For pseudoplastic liquids with variable viscosity of a product (non-Newtonian fluid), the shear stress is of a power-law nature. Figure 6 shows the distribution of strain of displacement on the yeast dough during kneading by the cam operating elements and, as a result, the distribution of the mechanical load for a certain position of the cam operating elements.

\section{Results}

To study the shear stress, four basic positions of the cam's working elements were selected, then these provisions are repeated on the shaft of the working element.

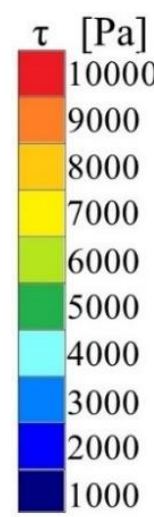

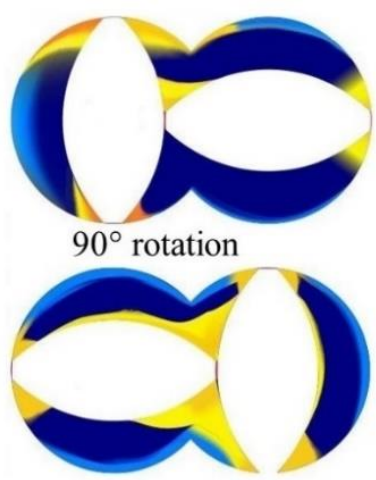

$180^{\circ}$ rotation

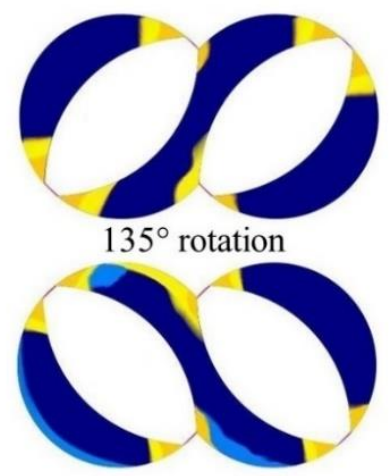

$225^{\circ}$ rotation

Figure 7. Change in the shear stress $[\tau, \mathrm{Pa}]$ in the mist chamber in the process of mixing the yeast dough by the cam operating elements

On the greater part of the working volume there are not large indicators of shear stress (Figure 7). The greatest indices of shear strain during modeling of the process of mixing the yeast dough are observed in the field of interaction of the working element with the wall of the case and in the zone of engagement of the working elements. In the area of the engagement of the working elements and at the contact with the walls of the chamber, the shear stress values reach from 7000 to $8000 \mathrm{~Pa}$. For the rest of the chamber, the displacement strain reaches $1000-3000 \mathrm{~Pa}$.

The dissociation is proportional to the displacement velocity squared. Due to dissipation, the conversion of the kinetic energy of the stream into the heat occurs due to internal friction of the yeast dough with the working elements and the case [11]. 
The yeast dough is mixed in 12 pairs of cams, which are shifted at an angle of $45^{\circ}$, for the dissipation process it was decided to consider the process of kneading in the example of 3-6-9-12 pair of cams, since at the beginning of mixing there were noticeable changes in dissipation. By means of simulation, distribution of dissipation in the microscope was considered in the process of mixing the yeast dough with the cam operating elements (Figure 8).

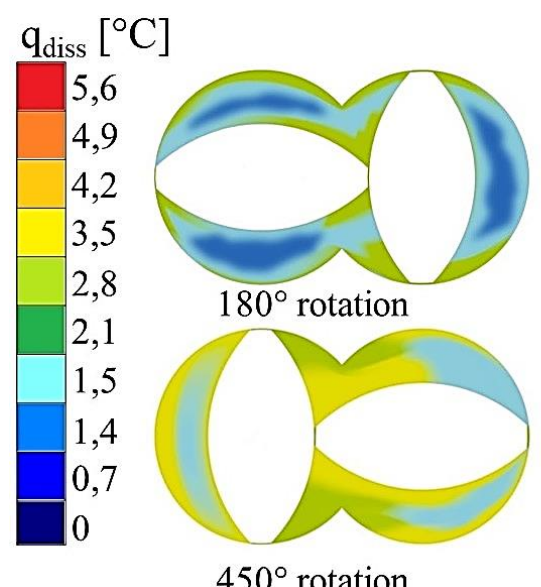

$450^{\circ}$ rotation

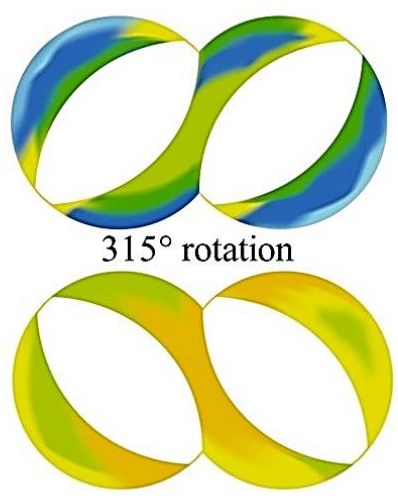

$585^{\circ}$ rotation

Figure 8. Distribution of dissipation $\left[q_{\text {diss, }},{ }^{\circ} \mathrm{C}\right]$ in the chamber in the process of mixing the yeast dough by the cam working elements

Distribution of dissipation clearly shows in which parts of the working chamber is the formation of heat in the flow area. In the area of kneading 3 pairs of cam ( $180^{\circ}$ rotation), there is no significant heat release, then during the mixing due to internal friction of the yeast dough with the working elements and the case there is an increase in the conversion of the kinetic energy of the stream into the heat and the temperature of the yeast dough increases. At the stamping site 12 pairs of cams, the temperature of the yeast dough increases by almost $5^{\circ} \mathrm{C}$, thus taking into account that before the start of the simulation, the initial temperature was set to $\mathrm{t}=30^{\circ} \mathrm{C}$, then at the end of mixing, this temperature in the yeast dough reaches almost $35^{\circ} \mathrm{C}$. The greatest amount of heat is observed in the sphere of cam involvement of the working elements.

Thus, the simulation parametric model of the process of mixing the yeast dough allowed to study in details the processes occurring in the mixing chamber of the dough, the dependence of the flow pattern on the design and configuration of the cam operating elements and the frequency of rotation [12].

The simulated parametric model of the process of mixing by cam operating elements, which allows to carry out design calculations effectively when choosing rational structural and technological parameters, is developed. Using the presented scientific and methodological developments will significantly accelerate and economically save the process of creating reliable process equipment for mixing yeast dough.

It is possible to rationalize the process of mixing the dough and reduce the time required for fumigation and fermentation by intensive mechanical processing of the dough by the cam operating elements and as a result of obtaining qualitative characteristics of the baking products.

It is advisable to mix the yeast dough with the use of the cam's working organs. 


\section{Checking the results on the physical model}

Model verification for adequacy was carried out using an experimental dual-action machine of continuous action (Figure 9).

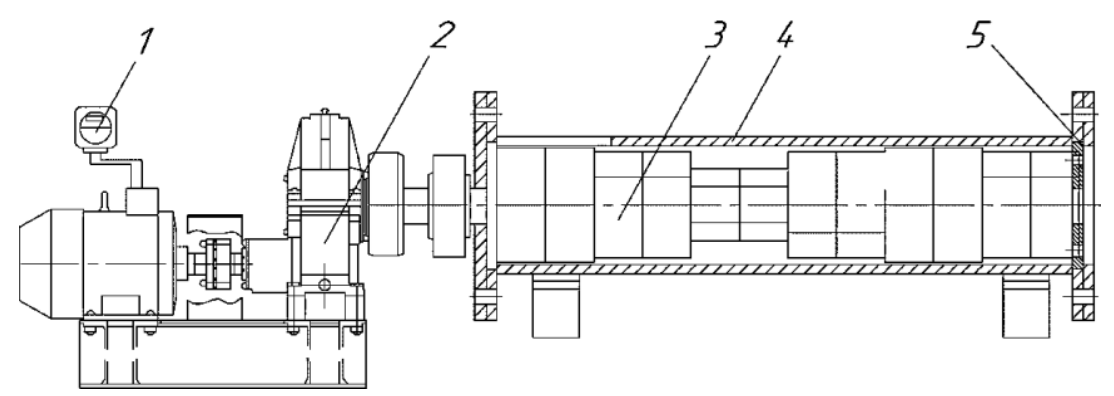

Figure 9. The scheme of an experimental installation with cam operating elements: 1 - a device for measuring electric power; 2 -drive; 3 -working element; 4 - frame; 5 - stabilizing grate.

The results of simulation of parametric modeling were tested on a physical model. Comparing the results (Figure 10-11) and performing mathematical processing, the error is less than 5\%, the mathematical model corresponds to the adequacy.

The experimental installation works as follows, the raw material enters the receiving hopper, after which, using the working bodies and their influence, the process of kneading is carried out, after which the dough comes out through the stabilizing grill.

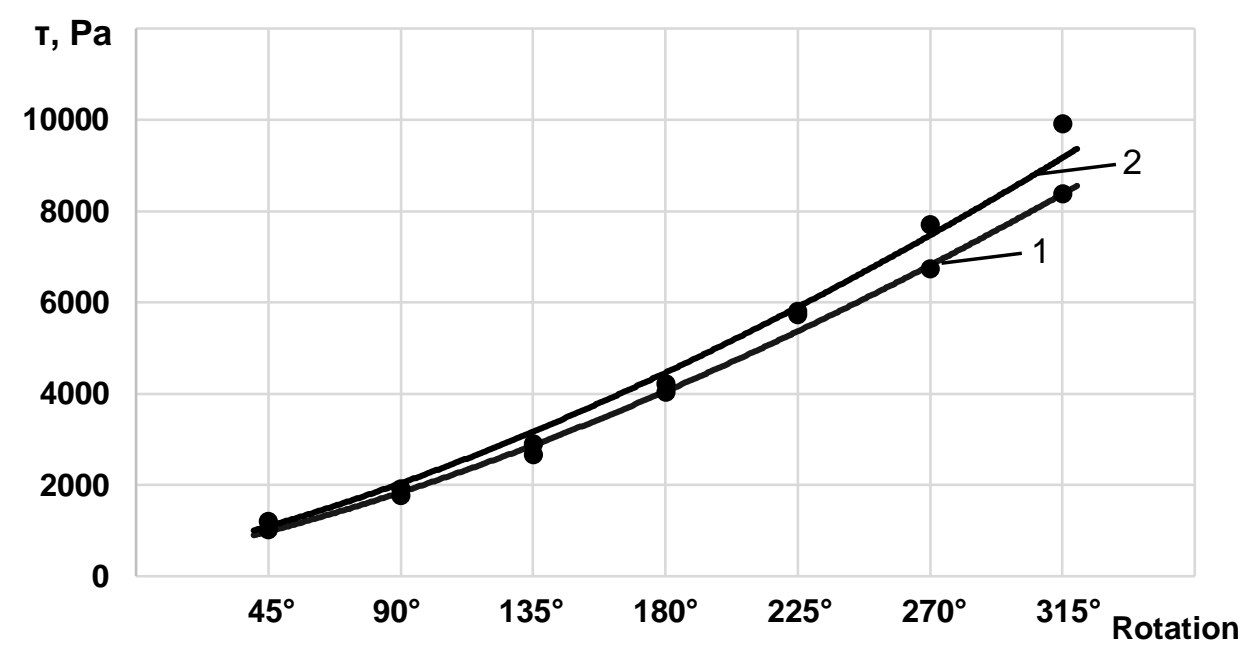

Figure 10. Comparison of the results of the physical and mathematical modeling of the displacement stress $[\tau, \mathrm{Pa}]$ in the mixing chamber at different angles of rotation of the cam element (1-imitation, 2 - physical) 


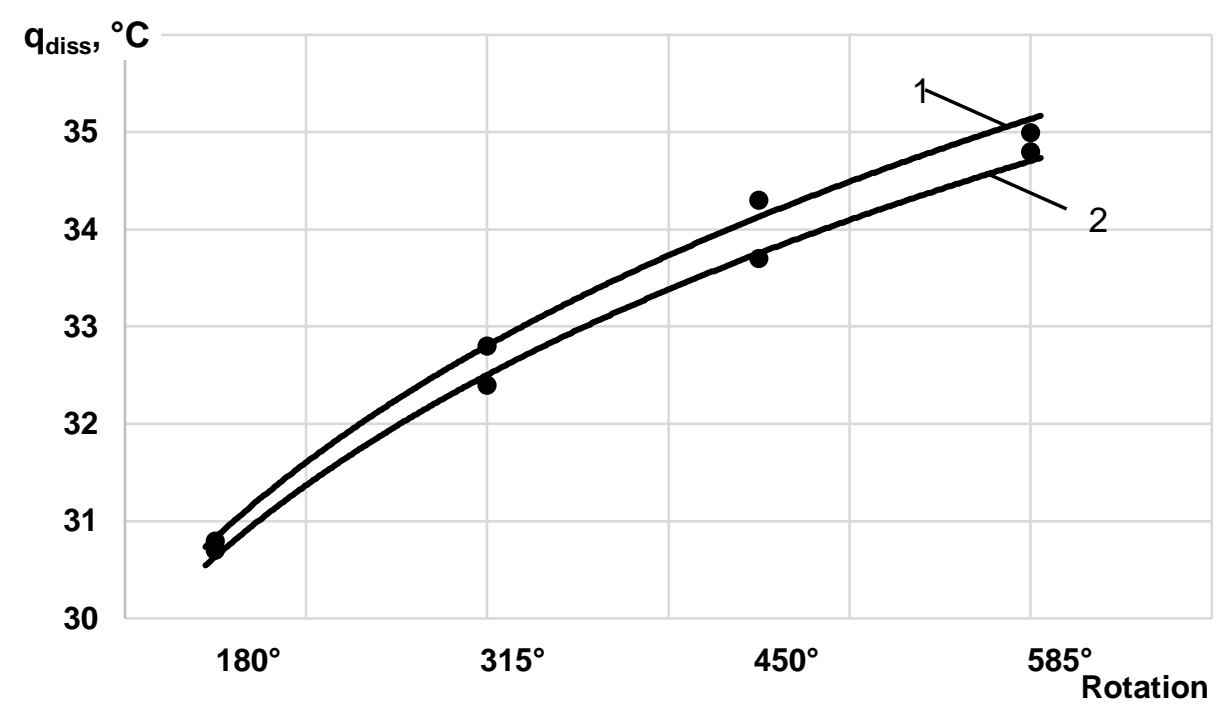

Figure 11. Comparison of the results of the physical and mathematical modeling of the distribution of dissipation $\left[\mathrm{q}_{\text {diss }},{ }^{\circ} \mathrm{C}\right]$ in the mixing chamber at different angles of rotation of the cam element (1-physical, 2-simulation)

The results of the computational experiments allowed to investigate the process of mixing the yeast dough by the cam operating elements in the stirring chamber. By means of simulation, the change in the stresses of the shift of the yeast dough in the stirring chamber was investigated, the distribution of dissipation in the chamber of stirring and the temperature change during the kneading process were investigated. It is determined that for a rotational speed of a working element of $60 \mathrm{rpm}$, the temperature of the yeast dough rises to $5^{\circ} \mathrm{C}$, which is admissible while kneading the dough. The obtained simulation results will be used to organize the technological process and design new equipment for mixing the yeast dough.

\section{Conclusions}

It was investigated the change of the stresses of the shift of the yeast dough in the stirring chamber, in the region of the contact between the working elements and at the contact with the walls of the chamber, the shear stresses reach from 7000 to $8000 \mathrm{~Pa}$, and the rest of the shrinkage chamber displaces a strain of 1000-3000 Pa. The distribution of dissipation in the chamber of stirring and the temperature change during the mixing process was investigated, and the temperature of the yeast dough was raised to $5^{\circ} \mathrm{C}$ for the rotation of the working element $60 \mathrm{rpm}$, which is admissible when kneading the dough.

On the basis of simulation modeling of the process of mixing the yeast dough, effective working elements are proposed for mixing the yeast dough in a dough machine of continuous action. 


\section{References}

1. Struck S., Straube D., Zahn S., Rohm H. (2018), Interaction of wheat macromolecules and berry pomace in model dough: Rheology and microstructure, Journal of Food Engineering, 223, pp. 109-115, DOI: 10.1016/j.jfoodeng.2017.12.011

2. Nawrocka A., Krekora M., Niewiadomski Z., Miś A. (2018), Characteristics of the chemical processes induced by celluloses in the model and gluten dough studied with application of FTIR spectroscopy, Food Hydrocolloids, 85, pp. 176-184, DOI: 10.1016/j.foodhyd.2018.07.020

3. Brandner S., Becker T., Jekle M. (2018), Wheat dough imitating artificial dough system based on hydrocolloids and glass beads, Journal of Food Engineering, 223, pp. 144151, DOI:10.1016/j.jfoodeng.2017.12.014

4. Zhang D., Mu T., Sun H. (2017), Comparative study of the effect of starches from five different sources on the rheological properties of gluten-free model doughs, Carbohydrate Polymers, 176, pp. 345-355, DOI: 10.1016/j.carbpol.2017.08.025.

5. Wang Y., Ye F., Liu J., Zhou Y., Zhao G. (2018), Rheological nature and dropping performance of sweet potato starch dough as influenced by the binder pastes, Food Hydrocolloids, 85, pp. 39-50, DOI: 10.1016/j.foodhyd.2018.07.001.

6. Šćepanović P., Goudoulas Th. B., Germann N. (2018), Numerical investigation of microstructural damage during kneading of wheat dough, Food Structure, 16, pp. 8-16, DOI: 10.1016/j.foostr.2018.01.003

7. Vanin F. M., Lucas T., Trystram G., Michon C. (2018), Biaxial extensional viscosity in wheat flour dough during baking, Journal of Food Engineering, 236, pp. 29-35, DOI: 10.1016/j.jfoodeng.2018.05.007.

8. Jiang Z., Liu L., Yang W., Ding L., Zhou S. (2018), Improving the physicochemical properties of whole wheat model dough by modifying the water-unextractable solids, Food Chemistry, 259, pp. 18-24, DOI: 10.1016/j.foodchem.2018.03.093

9. Shtefan E., Pashchenko B., Blagenko S., Yastreba S. (2018), Constitutive Equation for Numerical Simulation of Elastic-Viscous - Plastic Disperse Materials Deformation Process, Springer International Publishing AG, 380, pp. 356-363.

10. Stefan E.V., Miznik L.M. (2005), Mathematical modeling of coextrusion processes in the manufacture of tubular products with fillings, Scientific Works of National University of Food Technologies, 6(44), pp. 82-85.

11. Klemens K. (2007), Co-Rotation twin-screw extruders. Fundamentals technology and Application, Hanser.

12. Nawrocka A., Szymańska-Chargot M., Miś A., Wilczewska A. Z., Markiewicz K. H. (2017), Aggregation of gluten proteins in model dough after fibre polysaccharide addition, Food Chemistry, 231, pp. 51-60, DOI: 10.1016/j.foodchem.2017.03.117

13. Janssen F., Wouters A., Pauly A., Delcour J. (2018), Relating the composition and air/water interfacial properties of wheat, rye, barley, and oat dough liquor, Food Chemistry, 264, pp. 126-134, DOI: 10.1016/j.foodchem.2018.05.016

14. Zhang D., Mu T., Sun H. (2018), Effects of starch from five different botanical sources on the rheological and structural properties of starch-gluten model doughs, Food Research International, 103, pp. 156-162, DOI: 10.1016/j.foodres.2017.10.023

15. Yang F., Zhang M., Prakash S., Liu Y. (2018), Physical properties of 3D printed baking dough as affected by different compositions, Innovative Food Science \& Emerging Technologies, 49, pp. 202-210, DOI: 10.1016/j.ifset.2018.01.001 
16. Zhang Y., Li D., Yang N., Jin Z., Xu X. (2018), Comparison of dextran molecular weight on wheat bread quality and their performance in dough rheology and starch retrogradation, $L W T, 98$, pp. 39-45, DOI: 10.1016/j.lwt.2018.08.021

17. Cappelli A., Cini E., Guerrini L., Masella P., Parenti A. (2018), Predictive models of the rheological properties and optimal water content in doughs: An application to ancient grain flours with different degrees of refining, Journal of Cereal Science, 83, pp. 229-235, DOI: 10.1016/j.jcs.2018.09.006

18. Rachok V., Gudzenko V., Telychkun Y., Telychkun V. (2018), Formation of at wheat dough kneading, Scientific Works of National University of Food Technologies, 10(24), pp. 155-162, DOI: 10.24263/2225-2924-2018-24-2-19 